\title{
Maintenance optimization for warm standby system based on availability
}

\author{
Yutao Wu \& Liang Wen \\ Department of Management Engineering, Mechanical Engineering College P.R. China \\ Xinfeng $\mathrm{Yu}$ \\ China Satellite Maritime Tracking and Controlling Department P.R. China
}

Yachong Deng

Troopers' bureau of military representation P.R. China

ABSTRACT: To ensure low cost and high maintenance cost protection devices can be used for a long time. In order to improve availability of protection system, the methods of adding redundancy and periodic replacement are pro-posed. First we establish the equivalent model of cumulative failure probability and convert the wasting time of the spare part into the working time of the using part. Then, under the strategy of block replacement, we establish the availability model of infinite period with the maximum availability as the optimization objective. In case, we seek out the optimum replacement interval and verify the model's the applicability and validity through contrast and analysis. Finally, we give a brief discussion of future research area about warm standby system maintenance.

KEYWORD: Mathematical model; Warm standby system; Block replacement; Preventive maintenance

\section{INTRODUCTION}

Some of the important places and key equipment are usually equipped with protection device, such as smoke alarms, fuses, etc. Normally, the protection system is not working, once received a signal, the protection device will start. Usually, many protection devices are difficult to remove, inconvenient maintenance, and maintenance will also introduce fault. In addition, the general protection equipment with low cost and high maintenance cost, regular maintenance is not cost-effective. Generally, the reliability of the device is high, and the strategy of period replacement is a better choice.

In order to prolong the working time of the protective equipment and improve system availability, the methods of adding redundancy and periodic replacement are proposed. However, the age of spare parts , especially for electronic components, will be reduced in a standby state for a long time. This system which spare parts in the reserve period will fail, but the failure rate is lower than the using parts is called warm standby system (Gan M. Z, 2005).

In the early days, by using Markov process theory or Markov renewal process theory, some important reliability indices of the two-component redundant systems had been derived (Ascher H, 1984). Lam (Lam Y. 1988) first introduced a geometric process repair model to approach the deteriorating repairable systems. Under this model, two kinds of replacement policy for a one-component repairable system with one repairman were studied. Then, a lot of studies for the deteriorating systems were carried out by using the geometric process model (Pérez - Ocón R, 2002).After geometric process model was introduced, much research has been conducted (Wu S, 2005). Most of the research object of the standby system is reliability. However, Zhang T (Zhang T, 2006) studied the availability and reliability of kout-of-(M+N): G warm standby system. Wang K. H. (Wang K. H, 2006) analyzed the availability and reliability in four warm standby systems.

In this paper, the protection device is abstracted as a warm standby system consisting of two identical components. Through the method of mathematical modeling, we discussed the optimal replacement intervals under the block replacement policy.

\section{PRELIMINARIES}

\subsection{Problem description}

As is shown in Fig. 1, the warm standby system consists of two identical units. At first, the unit 1 is used. If the unit 1 fails, switch immediately, the unit 2 (spare part) accesses the system. If the system is available, it will not be maintained. When the two units are failure, both replaced. If the system is available, the two units are replaced simultaneously, until a predetermined period is reached. In the infinite Period, we determine the optimal replacement interval $\mathrm{T}$ for maximum system availability. 


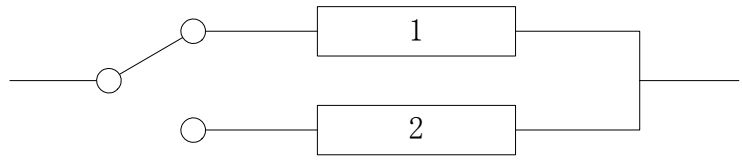

Figure 1 Warm standby system consisting of two identical units

\subsection{Notations}

$F_{1}(t)$ Distribution function of accumulated failure of the using unit unit

$f_{1}(t)$ Probability density function of the using

$F_{2}(t)$ Distribution function of accumulated failure of the spare part

$f_{2}(t)$ Probability density function of the spare part

$t_{1}$ : Fault occurrence time of the unit 1 in using

$t_{2}$ : Fault occurrence time of the unit 2 in store

$t_{3}$ : Actual age of the unit 2 under the cumulative failure probability equivalent conversion

$t_{21}$ : Equivalent use time of $t_{1}$

$t_{4}$ : Working time of the unit 2 under the cumulative failure probability equivalent conversion

$t_{\mathrm{p}}$ : Average time of preventive replacement

$t_{\mathrm{f}}$ : Average time of failure replacement

$T$ :Interval of the block replacement;

$A(T)$ : Average availability of the system for long term use, when block replacement policy under interval $\mathrm{T}$

$E U(T)$ : The expected value of the unavailable time of the system for long term use, when block replacement policy under interval $\mathrm{T}$

$\mathrm{n}$ : Number of failure units before each replacement

$U_{i}(T)$ : In one replacement cycle, the unavailable time of the system at the i times of the system failure when block replacement policy under interval $\mathrm{T}$

\subsection{Assumptions}

In order to solve the problem presented in Section 2.1, the following assumptions are made:

(1) Products are unrepairable. After replacing, both unit 1 and unit 2 are "as good as new".

(2) Preventive replacement according to the time interval $\mathrm{T}$, or after the failure to replace, $\mathrm{T}$ as a constant.

(3) In order to build more accurate models, considering the influence of maintenance time, corrective replacement time $t_{\mathrm{f}}$ is greater than preventive replacement $t_{\mathrm{p}}$. Replacement time is fixed.

(4) The response time of failure can be neglected, replace right away after failure. Switching is done in an instant and the switch will not fail.
(5) The failure rate are identical, units have the same distribution function in using.

\section{MODELING AND SOLUTION}

In order to simplify the analysis process and uniform variable, cumulative failure probability equivalent model is introduced. Convert the wasting time of the spare part into the working time of the using part. And then establish the optimization model of availability.

\subsection{Cumulative failure probability equivalent model}

As is shown in fig. 1, the warm standby system consists of two identical units. Their failure distribution functions are $F_{1}(t)$ and $F_{2}(t)$, respectively. Suppose: unit 1 failure at $t_{1}$ time. At this point, assume the unit 2 is not invalid. Under the same load conditions, the unreliability of the unit 2 is $F_{2}\left(t_{1}\right)$, and then the unit 2 accesses the system as the using unit. In continuing the work, the failure distribution function of element 2 is $F_{1}(t)$. At the beginning of the continuing work of the moment, the value of storage of $\mathrm{cu}-$ mulative failure probability will not change because of change of the cumulative failure distribution function (Yang W, 1990). Under the condition of storage, the cumulative failure probability is converted to the cumulative failure probability under the condition of using. As shown in Fig. 2. Cumulative failure probability equivalent model can be expressed as $\mathrm{F}_{2}\left(\mathrm{t}_{1}\right)=\mathrm{F}_{1}\left(\mathrm{t}_{21}\right)$

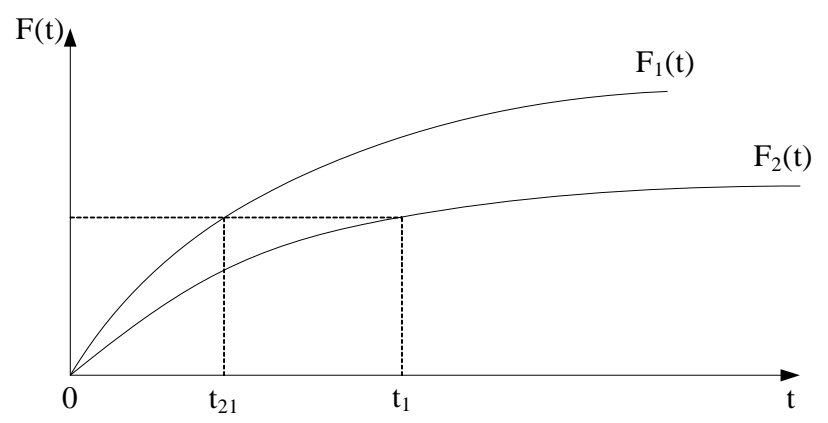

Figure 2 Cumulative Failure Probability Equivalent Model

\subsection{Replacement model for infinite period}

According to the basic theory of renewal process, In the long-term use conditions, the average availability of the system can be expressed as

$$
\begin{aligned}
& \mathrm{A}(\mathrm{T})=\frac{T-E U(T)}{T+\mathrm{t}_{p}} \\
& E U(T)=\sum_{i=0}^{n} U_{i}(T), n=0,1,2
\end{aligned}
$$

Before a replacement, there is no unit failure in the system, that is $t_{1}>T$ and $t_{2}>T$, 
$U_{0}(T)=0$

When $t_{1}<T$, unit 1 was failure at the time of $t_{1}$, the unit 2 accesses the system as the using unit. From formula (1), the unit 2 is equivalent to the working time length of $t_{21}$ under the condition of the failure distribution function $F_{1}(t)$. The equivalent working time of unit 2 can be expressed as

$t_{4}=t_{3}-t_{21}+t_{1}$

Before a replacement, there is one unit failure in the system. The first case is $t_{1}<T, t_{2}>t_{1}$ and $t_{4}>T$. The second case is $t_{1}>T$ and $t_{2}<T$, $U_{1}(T)=0$

In a replacement interval, when the two units are both failure, the two units are replaced simultaneously. $E N_{\mathrm{b}}(T)$ is the number of failures in $[0, t]$. It is expected with the use of a fault distribution function $F_{1}(t)$ corresponding to the renewal process. Expected failure times of the system could be expressed as

$E N_{\mathrm{b}}(T)=\int_{0}^{T-t_{f}}\left[1+E N_{\mathrm{b}}\left(T-t_{f}-t\right)\right] d F_{1}(t)$

There are two cases of two units both fail.

The first case, before a replacement, when the unit 1 fails, the unit 2 has failed. That is $t_{1}<T$ and $t_{2}<t_{1}$,

$U_{2 a}(T)=\left\{\begin{array}{l}P_{r}\left(t_{1}<T\right) P_{r}\left(t_{2}<t_{1}\right) . \\ \int_{0}^{T} \int_{0}^{t_{1}}\left(T-t_{1}\right) d F_{2}\left(t_{2}\right) d F_{1}\left(t_{1}\right), \quad T \leq t_{f} \\ P_{r}\left(t_{1}<T\right) P_{r}\left(t_{2}<t_{1}\right) . \\ {\left[\int_{0}^{T-t_{f}} \int_{0}^{t_{1}}\left(t_{f}+E t_{f}\left(T-t_{f}-t_{1}\right) d F_{2}\left(t_{2}\right) d F_{1}\left(t_{1}\right)\right.\right.} \\ \left.+\int_{T-t_{f}}^{T} \int_{0}^{t_{1}}\left(T-t_{1}\right) d F_{2}\left(t_{2}\right) d F_{1}\left(t_{1}\right)\right], \quad T>t_{f}\end{array}\right.$

The second case, before a replacement, after the unit 1 fails, the unit 2 works. But before the next replacement, the component 2 will fail. That is $\mathrm{t}_{1}<T, t_{2}>t_{1}$ and $\mathrm{t}_{4}<T$,

$U_{2 b}(T)=\left\{\begin{array}{l}P_{r}\left(t_{1}<T\right) P_{r}\left(t_{2}>t_{1}\right) P_{r}\left(t_{4}>T \mid t_{3}>t_{21}\right) . \\ \int_{0}^{T} \int_{0}^{t_{4}}\left(T-t_{4}\right) d F_{2}\left(t_{2}\right) d F_{1}\left(t_{4}\right), \quad T \leq t_{f} \\ P_{r}\left(t_{1}<T\right) P_{r}\left(t_{2}>t_{1}\right) P_{r}\left(t_{4}>T t_{3}>t_{21}\right) . \\ {\left[\int_{0}^{T-t_{f}} \int_{0}^{t_{4}}\left(t_{f}+E t_{f}\left(T-t_{f}-t_{4}\right) d F_{2}\left(t_{2}\right) d F_{1}\left(t_{4}\right)\right.\right.} \\ \left.+\int_{T-t_{f}}^{T} \int_{0}^{t_{4}}\left(T-t_{4}\right) d F_{2}\left(t_{2}\right) d F_{1}\left(t_{4}\right)\right], \quad T>t_{f}\end{array}\right.$

\subsection{Model optimal solution}

This paper establishes the availability model of warm standby system consisting of two identical components in the block replacement strategy. It could not be solved directly, because the representation of the model is too complicated. Numerical al- gorithm is used to solve the simulation by MATLAB software.

\section{EXAMPLE ANALYSIS}

Suppose:

$F_{1}(\mathrm{t})=1-\exp \left[-(t / 70)^{2}\right]$

$F_{2}(\mathrm{t})=1-\exp \left[-(t / 300)^{2}\right]$

$t_{p}=2$

$t_{\mathrm{f}}=5$

In the infinite Period, the expected availability of the system can be solved by MATLAB software. As shown in Fig. 3

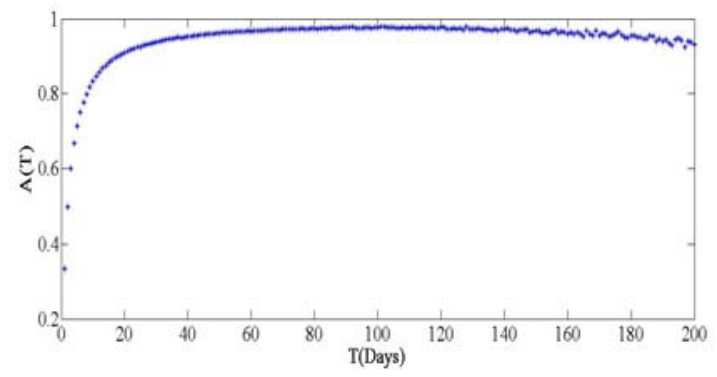

Figure 3 The relationship between availability and replacement interval for warm standby system

The highest point in the graph is the maximum availability of the system. It is 0.9764 . The best replacement interval is 103 days. When the replacement intervals are in the range of 39-178 days, the availability is greater than 0.95 .

Fig. 4 describes the relationship between availability and replacement interval for single component system. The cumulative distribution function of the single unit is $F_{1}(t)$.

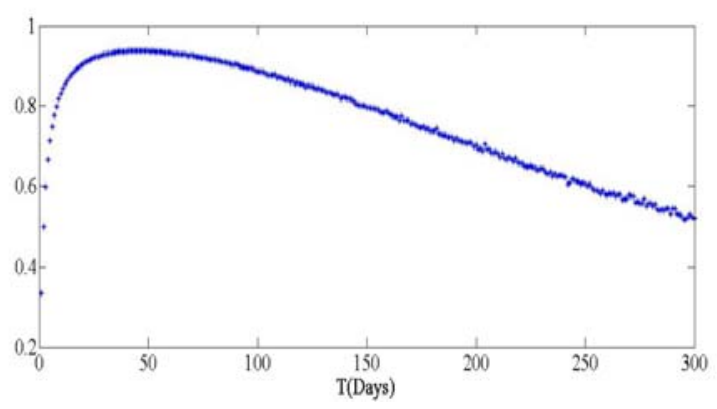

Figure 4 The relationship between availability and replacement interval for single component system

The highest point in the graph is the maximum availability of the system. It is 0.9384 . The best replacement interval is 46 days. When the replacement intervals are in the range of 19-93 days, the availability is greater than 0.9 . 
Comparison of Fig. 3 and fig. 4, we found that the maximum availability of a single component system is lower than the maximum availability of the system, Moreover, the warm standby system can maintain a high degree of availability in a long time, but the availability of single unit system is rapidly declining. In summary, the warm standby system can improve the availability of the system in a longer replacement interval.

\section{CONCLUSIONS}

In this paper, the availability of protection system is improved by adding redundancy. A proper model is established and the effective method is adopted. The validity and applicability of the model are verified by the comparative analysis of the case. Standby systems are diverse and the factors considered are complex. In this paper, only a simple system is discussed. Next, we will discuss the research on the replacement intervals of the warm standby system under the condition of infinite interval.

\section{ACKNOWLEDGEMENTS}

Constructive comments and suggestions from anonymous reviewers and editor are very much appreciated.

\section{REFERENCES}

Ascher H. \& Feingold H. 1984. Repairable Systems Reliability. Marcel Dekker.

Barlow R.E. \& Proschan F. 1965 Mathematical Theory of Reliability. Wiley.

Gan M. Z. \& Kang J. S. \& Gao Q. 2005. Military Equipment Maintenance Engineering, Beijing: National Defence Industry Press.

Jia X. S.2007. The Decision Models for Reliability Centered Maintenance. National Defence Industry Press.

Lam Y. 1988. Geometric processes and replacement problem. Acta Mathematicae Applicatae Sinica, (4): 366-377.

Lam Y. 1988. A note on the optimal replacement problem. Advances in Applied Probability, 479-482.

Pérez - Ocón R. \& Torres - Castro I. 2002. A reliability semi - Markov model involving geometric processes. Applied Stochastic Models in Business and Industry, 18(2): 157-170.

Wu S. \& Clements-Croome D. 2005. Optimal maintenance policies under different operational schedules. IEEE Transactions on Reliability, 54(2): 338-346.

Wang K. H. \& Dong W. L. \& Ke J. B. 2006. Comparison of reliability and the availability between four systems with warm standby components and standby switching failures, Applied Mathematics and Computation, 183(2): 1310-1322.

Yang W. M. \& Sheng Y. X. 1990. System Reliability Digital Simulation, University of Aeronautics and Astronautics Press.
Zhang Y. L. 2002. A geometric-process repair-model with good-as-new preventive repair, IEEE Transactions on Reliability, 51(2): 223-228.

Zhang Y. L. \& Wang G. J. 2007. A deteriorating cold standby repairable system with priority in use, European Journal of Operational Research, 183(1): 278-295.

Zhang T. \& Xie M. \& Horigome M. 2006. Availability and reliability of k-out-of-(m+n): G warm standby systems, Reliability Engineering \& System Safety, 91(4): 381-387. 